\title{
Cyclodimerization of Stilbenes and Styrenes Catalyzed by Heteropolyacid Supported on Silica
}

\author{
E.N. Alesso ${ }^{1}$, J. Aguirre $^{2}$, B. Lantaño ${ }^{1}$, L. Finkielsztein ${ }^{1}$, G.Y. Moltrasio ${ }^{2}$, P.G. Vázquez $^{3}$, L.R. \\ Pizzio $^{3}$, C. Caceres ${ }^{3}$, M. White ${ }^{3}$ and H.J. Thomas ${ }^{3}$ \\ ${ }^{1}$ Química Orgánica III. Fac. de Farmacia y Bioquímica. UBA. Junín 956 (1113). Bs. As. Argentina \\ ${ }^{2}$ Dpto. de Ciencias Básicas. U N Lu. Luján. Argentina \\ ${ }^{3}$ CINDECA, UNLP-CONICET, 47 No 257, 1900 La Plata, Argentina \\ E-mail: gmolta@ffyb.uba.ar
}

\begin{abstract}
Several stilbenes and styrenes have been treated with heteropolyacid] (HPA) supported over silice. The compounds obtained were characterized by ${ }^{1} \mathrm{H}$ and ${ }^{13} \mathrm{C}$ - NMR and the yields were compared with those obtained using $\mathrm{H}_{2} \mathrm{SO}_{4}$ (c) and ethyl poliphosphate] (PPE).
\end{abstract}

\section{Introduction}

The cyclodimerization of stilbenes and styrenes with acid reagents have been thoroughly descripte in the literature. We have observed that the formation of indanes and/ or tetralines from estilbenes for treatment with as acid differents as the $\mathrm{H}_{2} \mathrm{SO}_{4}$ (c) and PPE relies on the substitution of the aromatic rings [1]. In this work it are introduced the study of the behavior of several stilbenes and styrenes in presence of Molybdophosphoric acid (AMP) and tungstophosphoric (ATP) supported on sílice [2].

\section{Experimental}

The catalyst was prepared on base the AMP and APT acids supported on sílice employing the technique of impregnation in equilibrium during $72 \mathrm{hs}$. The support employing was $\mathrm{SiO} 2 \mathrm{Grace}$. The catalysts was dried to $25^{\circ} \mathrm{C}$, calcined to $200^{\circ} \mathrm{C}$ and washed with chloroform, where it was carried out the cyclodimerization reaction. The contents of AMP and ATP, of the washed catalysts, was from 0.39 and $0.37 \mathrm{~g} / \mathrm{g}$ of respectively catalyst. To the chloroform solution of stilbenes and styrenes was added the catalyst ( 0.1 meq./ meq. of reagent). The mixture was heated at refluxe. The reaction was followed for t.l.c. The catalyst was filtered and the solvent evaporated under reduced pressure. The products of reaction were purified and identified by physics and spectroscopy dates. The catalysts were washed with chloroform and reused with the same effectiveness until four time. 


\section{Results and Discussion}

The results obtained in the reactions of cyclodimerization of stilbenes and styrenes have resulted extremely satisfactory. The two catalysts showed a similar behavior in these reactions. The conditions of reaction were soft and the yield very good (80-100\%). The formation of lateral products is not observed, which facilitates the purification.<smiles>[R3]C=Cc1ccc([R2])c([R])c1</smiles>

$\mathrm{R}_{1} ; \mathrm{R}_{2}: \mathrm{H}, \mathrm{OCH}_{3}, \mathrm{OCH}_{2} \mathrm{O}$

$\mathrm{R}_{3}: \mathrm{CH}_{3}$ o Arilo<smiles>[R3]CC1c2cc([R2])c([R])cc2C(c2ccc([R])c([R2])c2)C1[R3]</smiles><smiles>[R]c1ccc(C2c3cc([R])c([R])cc3CC([R3])C2[R3])cc1[R]</smiles>

Acknowledgements: The authors thank the economical aid of ANPCyT, SECYT (UBA) and CONICET.

\section{References and Notes}

1. Aguirre, J. M.; Alesso, E. N.; Moltrasio, G. Y. J. Chem. Soc. Perkin. Trans I 1999, 1-6.

2. Kozhevnikov, J. V. Catal. Rev-Sci. Eng 1995, 37 (2), 311-352. 